\title{
INFLUÊNCIA DA PROPRIEDADE FAMILIAR NA ESTRUTURA E CUSTO DE CAPITAL DAS EMPRESAS BRASILEIRAS
}

\section{INFLUENCE OF FAMILY OWNERSHIP ON THE STRUCTURE AND COST OF CAPITAL OF BRAZILIAN COMPANIES}

\author{
ROBERTO WILDNER \\ Universidade do Oeste de Santa Catarina. Endereço: Avenida Euclides da \\ Cunha, 459, apto 202 | Centro | 89874-000| Maravilha/SC | Brasil. \\ (1) http://orcid.org/0000-0002-1584-2812 \\ roberto.wildner@unoesc.edu.br
}

\section{IEDA MARGARETE ORO}

Universidade do Oeste de Santa Catarina. Endereço: Rua Nereu Ramos, 3777D | Seminário | 89813-000 | Chapecó/SC | Brasil.

(1) http://orcid.org/0000-0002-2239-531X

ieda.oro@unoesc.edu.br

\author{
DAVID RODRIGO PETRY \\ Universidade do Oeste de Santa Catarina. Endereço: Rua Castro Alves, $191 \mid$ \\ Centro |89820-000| Xanxerê/SC | Brasil. \\ (D) http://orcid.org/0000-0001-5160-5083 \\ david.petry@unoesc.edu.br
}

\section{RESUMO}

Este estudo mensura a influência da propriedade na estrutura de capital das empresas familiares, comparando com as empresas não familiares, listadas na B3. As relações existentes entre estas variáveis são alvo de discussões e não há na literatura um consenso quanto à influência exercida pela gestão familiar na estrutura de capital. Para tanto, este estudo caracteriza-se como descritivo com abordagem quantitativa. Os dados foram resgatados da base de dados Economatica e a amostra consistiu de 269 empresas entre as familiares e não familiares. A revisão de literatura gerou 6 hipóteses que observaram as dimensões de propriedade, endividamento e custo de capital. Os dados foram tratados e analisados com auxílio do software SPSS, mediante estatística descritiva, correlação e regressão linear. Os resultados demonstram que o Endividamento a Longo Prazo e o Endividamento Total apresentaram coeficientes negativos, o que denota uma relação inversamente proporcional entre eles e a gestão familiar. Na regressão, os resutados apontam que as dimensões de propriedade na gestão familiar e a concentração acionária influenciam significativamente no endividamento das empresas. Denota-se uma tendência de que essa influência em empresas familiares torna-se mais significativa quando avaliada em aspectos de longo prazo. Mesmo com essa característica, empresas familiares tendem a apresentar-se menos endividadas se comparadas às demais. O controle acionário nelas não se mostrou significante nas análises propostas. E a relação entre gestão familiar, concentração acionária e controle acionário com o custo de capital não demonstrou significância, divergindo de outros estudos que evidenciaram significativas influências nessas relações. Ao final são apresentadas limitações e sugestões para novas investigações. 
Palavras-chave: Propriedade Familiar. Estrutura de Capital. Custo de Capital. Endividamento.

\begin{abstract}
The present study measures the influence of ownership on the capital structure of family businesses, compared to non-family businesses, listed in B3. The existing relations between these variables are the subject of discussions and there is no consensus in the literature regarding the influence exerted by family management on capital structure. For such, this study is characterized as descriptive, with a quantitative approach. Data have been retrieved from the Economatica database and the sample consisted of 269 companies, including family and non-family. The literature review generated 6 hypotheses, which observed the dimensions of ownership, indebtedness and cost of capital. Data have been processed and analyzed using the SPSS software, using descriptive statistics, correlation and linear regression. Results show that Long Term Debt and Total Debt presented negative coefficients, which denotes an inversely proportional relation between them and family management. As for the regression, results show that the dimensions of ownership in family management and shareholding concentration significantly influence the indebtedness of companies. There is a trend that this influence on family businesses becomes more significant when evaluated in long-term aspects. Even with this characteristic, family businesses tend to be less indebted compared to others. Their shareholding control was not significant in the proposed analyzes. And the relation between family management, ownership concentration and ownership control with cost of capital was not significant, diverging from other studies that have shown significant influences in these relations. At the end, limitations and suggestions for further investigations are presented.
\end{abstract}

Keywords: Family property. Capital Structure. Capital Cost. Indebtedness.

\title{
1 INTRODUÇÃO
}

Estudos têm revelado diferenças entre o tipo de gestão familiar e não familiar, principalmente na forma de financiamento, na aversão ao risco e no desempenho superior (McConaughy, Matthews, \& Fialko, 2001; Charbel, Elie, \& Georges, 2013; Moura, 2014). LópezGracia e Sánchez-Andújar (2007) constataram menor custo de financiamento do capital em empresas familiares em virtude do uso dos recursos internos e do comportamento financeiro dos membros familiares. Evidências empíricas sugerem que a propriedade familiar está associada a um custo de agência inferior de financiamento [cerca de 32\% menor] do que em empresas não familiares, indicando que a propriedade familiar reduz o custo de financiamento das dívidas (Anderson, Mansi, \& Reeb, 2003).

Contudo, essa tendência não representa unanimidade. Estudo recente de Kayo, Brunaldi, e Aldrighi (2018) revela uma perspectiva diferente, afirmando que companhias familiares tendem a apresentar maior endividamento porque seus gestores são mais confiantes e otimistas do que gestores de empresas não familiares. Os autores complementam que gestores otimistas tendem a superestimar o dinheiro e o fluxo futuro de suas empresas; e gestores excessivamente confiantes tendem a subestimar o risco da empresa, levando à sobrevalorização do desempenho futuro da empresa e valor presente.

Uma característica da empresa familiar no que diz respeito à gestão revela distinção com a presença dos membros da família no conselho de administração. Os acionistas podem ser famílias ou indivíduos, fundos, instituições financeiras ou outra empresa e são responsáveis por diferentes tipos de escolhas estratégicas, podendo participar com diferentes percentuais de participação acionária (La Porta, Lopez-De-Silanes, \& Shleifer, 1999; Hautz, Mayer, \& Stadler, 2013). 
González, Guzmán, Pombo, e Trujillo (2013) indicam que quando as famílias estão presentes no conselho de administração, os níveis de dívida tendem a ser menores, o que sugere que os diretores da família são mais avessos ao risco.

Nas empresas de propriedade familiar e com gestão familiar existe uma maior possibilidade de alinhamento entre os interesses dos gestores e os interesses dos proprietários (McConaughy et al., 2001). Erbetta, Menozzi, Corbetta, e Fraquelli (2013) afirmam que as relações familiares, presentes na gestão da empresa, normalmente dão indícios de melhor desempenho, pois fornecem confiança para os gestores na tomada de decisão. Da mesma forma, a relação familiar dos membros do conselho de administração e controladores por meio de laços familiares, amizade, relações comerciais revelam-se mecanismos que criam valor para a empresa familiar (San Martin-Reyna \& Duran-Encalada, 2012). A concentração familiar e a presença histórica de familiares na empresa sugerem que as estratégias são de riscos reduzidos, menor diversificação acionária e níveis de dívida mais baixos (Anderson \& Reeb, 2003).

As empresas familiares são associadas a baixos níveis de dívida, por algumas razões, entre elas: a propriedade e a presença de membros familiares na gestão podem exercer maior influência sobre os níveis de financiamento da empresa. Com base nos achados inconclusivos, o contexto investigativo aponta para novas pesquisas. Diante das evidências, surge o seguinte problema de pesquisa: Qual a influência da propriedade (controle, concentração e gestão) na estrutura de capital (endividamento e custo de capital) das empresas familiares listadas na B3? Nesse sentido, o objetivo do estudo é mensurar a influência da propriedade (controle, concentração e gestão) na estrutura de capital (endividamento e custo de capital) das empresas familiares, comparando com as empresas não familiares, listadas na B3.

A justificativa para a realização da pesquisa se apoia no fato de ser um assunto recorrente, porém ainda inconclo quanto à temática. A contribuição científica deste estudo está atribuída na compreensão e melhor entendimento da influência da estrutura de propriedade na estrutura de capital das empresas familiares listadas na B3. Com os resultados pode-se compreender os efeitos da família no endividamento e no custo de capital das empresas que compõem o mercado acionário brasileiro.

\section{REVISÃO DE LITERATURA E HIPÓTESES DA PESQUISA}

\subsection{Gestão nas empresas familiares}

Estudos revelam que as empresas familiares tendem a ser mais conservadoras na sua gestão. López-Gracia e Sánchez-Andújar (2007) indicam a preferência de uso de recursos internos para financiamento, menos investimento em ativos intangíveis, um menor nível de dívida, alta concentração de capital quando geridas por uma família. As empresas com alguma influência familiar tendem a ser menos endividadas do que as companhias não familiares, ou seja, mais conservadoras, ao priorizar o capital próprio nas decisões de investimentos (Segura, Formigoni, \& Merofa, 2013).

Hsu, Lin, e Tsao (2018) sugerem que os proprietários de empresas familiares têm outros laços além do econômico para com suas empresas. Como consequência, os proprietários da família são motivados a monitorar a gestão intensivamente, protegendo os interesses de forma conservadora. O desafio para as famílias de negócios é que os papéis de família, propriedade e negócios envolvem valores diferentes e, por vezes, conflitantes. Os executivos da empresa preocupam-se com a estratégia e reputação de sua empresa no mercado, já os proprietários estão interessados em capital e desempenho financeiro em termos de criação de riqueza (Dyer, 1988).

As empresas familiares também podem ser geridas por pessoas que não são membros da família (Bernhoeft, 2004). Os membros da família também podem ser empregados. O funcionário também revelam preocupações com o capital social (reputação) e o capital emocional (oportunidades de carreira, gratificações e medidas de desempenho justas) (Aronoff, McClure, \& 
Ward, 2011). Nas empresas que estão no mercado de capitais, a gestão é compartilhada entre CEOs familiares e CEOs profissionais, gerando maior descentralização, autonomia e decisões alinhadas aos próprios interesses. Gao e Jain (2011) fornecem argumentos para apoiar um efeito positivo do CEO fundador no desempenho das organizações, justificado pelo potencial para reduzir os custos de agência, assim como os laços psicológicos e a identificação com a empresa, além de maior participação acionária e investimento de longo prazo, quando comparados a CEOs não familiares.

A pesquisa de Adams, Almeida e Ferreira (2009) alude um efeito positivo em relação ao controle por parte do fundador em grandes corporações norte-americanas, sugerindo que as empresas familiares apresentam melhor desempenho quando o CEO é um dos fundadores. Os mecanismos internos de governança corporativa (preconizados pela Teoria da Agência) atuam no desempenho organizacional. Empresas que separam a propriedade e o controle utilizam-se dos mecanismos de controle para promover o alinhamento de interesses entre principal e agente, para reduzir seus custos de agência. Diretores e conselheiros interagem em outras empresas, compartilhando o interlocking, com a finalidade de, quando positivo, trazer benefícios ao monitoramento, e podem ter maior poder/prestígio e obterem melhores informações sobre a capacidade dos agentes dentro do grupo (Dal Vesco \& Beuren, 2015).

De maneira geral, a presença de membros familiares na gestão é um fator importante para a empresa ser considerada como familiar. Outro fator presente para definir a empresa como familiar é quando a família tem intenção na continuidade da organização e na concentração de poder das gerações futuras.

\subsection{Propriedade nas empresas familiares}

A estrutura de propriedade está diretamente relacionada com o percentual de votos que o acionista controlador possui, sendo que, para definir as empresas familiares, a família ou membros da família devem possuir, no mínimo, $10 \%$ das ações ordinárias com direito a voto (La Porta et al., 1999). A propriedade pode incluir membros da família, investidores e/ou proprietários - que está preocupado com o capital financeiro (o desempenho dos negócios e dividendos) (Aronoff $e t$ al., 2011).

As empresas familiares no mercado de capitais se depararam cada vez mais com a pulverização do capital. Na empresa de propriedade familiar, uma pessoa pode ser o acionista controlador, isto é, uma pessoa (ao invés de um estado, sociedade, confiança gestão, ou fundo mútuo) pode reunir ações suficientes para garantir pelo menos $20 \%$ dos direitos de voto e a maior percentagem de direitos de voto, em comparação com outros acionistas (Bethlem, 2004).

Nas empresas familiares que podem ter proprietários que não são membros da família, seus membros são frequentemente envolvidos nas operações de seu negócio, e em empresas de menor porte, geralmente, um ou mais membros da família são os oficiais superiores e gestores (Bernhoeft, 2004).

Se, por um lado, ocorre alto grau de concentração da propriedade, o que resulta em um maior interesse de acionistas controladores em coletar informações e monitorar a atividade gerencial, pressionando os gestores por melhores resultados, por outro lado, a presença de acionistas majoritários e a busca por benefícios privados de controle, à custa da expropriação dos demais investidores, pode comprometer desde a gestão até processos de reestruturação, resultando em perdas de desempenho e geração de valor (Claessens, Djankov, Fan, \& Lang, 2002, Fonseca \& Silveira, 2016).

\subsection{Controle nas empresas familiares}

O crescimento das organizações e o desenvolvimento da economia mundial foram determinantes para a separação entre propriedade e controle nas empresas contemporâneas. Para maximizar suas riquezas, os investidores contratam pessoas especializadas para administrar suas organizações (Ribeiro, Colauto, \& Clemente, 2016). 
Guerrero e Barrios (2013) definem que uma família pode efetivamente controlar as operações da empresa quando possuir mais de $50 \%$ das ações com direito a voto e, ainda, ter membros da família ocupando posições relevantes na gestão, enquanto conselho de administração. Fonseca e Silveira (2016) mencionam que a estrutura de propriedade pulverizada é uma realidade majoritariamente adstrita ao contexto anglo-saxão. Na grande maioria dos países, inclusive no Brasil, a estrutura societária é altamente concentrada, observando-se uma sobreposição entre controle e gestão nas companhias.

Em grande medida, em razão da necessidade de captar recursos para financiamento do investimento, o processo de constituição das grandes corporações contemporâneas esteve estreitamente associado à dispersão da estrutura acionária. A separação entre propriedade e controle exigiu a transferência da autoridade quanto à tomada de decisão dos acionistas para os executivos, com isso, originaram-se os custos associados ao conflito de interesses (Fonseca \& Silveira, 2016).

Existem três formas principais de reduzir a propriedade sem perder o controle. A primeira é a emissão de ações sem direito a voto ou com direitos inferiores de voto (ações preferenciais, no caso do Brasil). O segundo mecanismo são os acordos de acionistas sobre o exercício do direito de voto ou do poder de controle. E, por fim, podem ser usados mecanismos de participação cruzada, em que uma empresa controlada por outra possui ações de sua controladora (Carvalhal da Silva, 2006).

A separação entre propriedade e controle é mais evidente e acelerada nos países que desenvolveram regulamentações que garantem aos investidores maior proteção legal, respeitando os princípios da transparência, equidade e responsabilidade corporativa, entre outros. Logo, existe a necessidade de um conjunto de regras que normatize as relações entre os gestores e os acionistas, amenizando os conflitos de interesse entre estes e aqueles (Sampaio, Lima, Cabral, \& Paula, 2014).

\section{METODOLOGIA}

Nesta seção aborda-se a fundamentação das hipóteses elaboradas para a pesquisa, e na sequência descreve-se os procedimentos metodológicos realizados no intuito de alcançar os objetivos propostos.

\subsection{Hipóteses da pesquisa}

La Porta, Lopez de Silanes, e Shleifer (1999) analisaram a estrutura de propriedade das 20 maiores empresas de capital aberto de 27 países com as economias geralmente mais ricas no mundo. Constataram que os acionistas controladores têm poder significativo nas empresas, principalmente pela participação na administração.

Conforme Formigoni et al. (2013), as empresas com alguma influência familiar são menos endividadas do que as companhias não familiares, ou seja, as empresas familiares tendem a ser mais conservadoras ao priorizar o capital próprio nas decisões de investimentos. Oliveira, Olyveira, e Souza (2013) compararam o nível de endividamento das empresas sob a influência da gestão e controle familiar com aquelas que possuem gestão profissional, dentro de diversos setores da economia brasileira. Entre os achados, as empresas familiares do setor agropecuário não possuem um consenso em relação à estrutura de capital, porém tendem a ser menos endividadas no curto prazo e no endividamento total quando comparadas às não familiares. A partir das evidências empíricas, apresenta-se o primeiro grupo de hipóteses da pesquisa:

H1a: As empresas que possuem membros familiares na gestão influenciam o endividamento inferior, quando comparadas com empresas de gestão não familiar;

H1b: As empresas que possuem concentração acionária familiar influenciam o endividamento inferior, quando comparadas com empresas de concentração não familiar; 
H1c: As empresas que possuem controle acionário familiar influenciam o endividamento inferior, quando comparadas com empresas não familiares.

De acordo com Moura (2014), o número de pesquisas relacionadas à estrutura de propriedade familiar alargou significativamente após os estudos de La Porta et al. (1999), Claessens, Djankov, e Lang (2000) e Faccio e Lang (2002). Esses estudos demonstraram que, normalmente, as famílias não realizam investimentos de modo diversificado, dessa maneira, a maior parte de sua riqueza privada se encontra na empresa controlada pela família. Consequentemente, eles têm fortes incentivos econômicos para valorizar o controle acionário, monitorar os gestores e diminuir os custos de agência (Moura, 2014).

Crisóstomo e Pinheiro (2015) investigaram se a concentração de propriedade tem efeitos na estrutura de capital de 2.266 empresas não financeiras que negociaram ações na BM\&Fbovespa, no período de 1996 a 2012. Os achados apontam que a concentração de propriedade favorece o endividamento das empresas. A realidade pode estar relacionada às possíveis insuficiências de caixa para financiar os projetos de investimentos. Constatou-se ainda que a concentração de propriedade apresenta um efeito positivo até certo ponto, a partir do qual o excesso de concentração prejudica a capacidade de financiamento por dívida.

Lanzarin (2017) revela alinhamento de interesses na perspectiva da Teoria da Agência para as empresas com estrutura de propriedade e gestão familiar. E ainda, que o efeito desse alinhamento se reflete no custo de financiamento da dívida com tendência de um valor reduzido quando comparado às empresas com gestão profissional.

Para sustentar o segundo grupo das hipóteses, este estudo apoia-se em McConaughy et al. (2001). Os autores sugerem que as empresas familiares controladas pela família fundadora têm maior valor e são operadas de maneira mais eficiente, assim como apresentam endividamento menor do que as empresas não familiares. Os autores sugerem que é o controle familiar da empresa, ao invés da gestão, a chave para as diferenças.

A partir dos estudos mencionados acima, pretende-se testar as afirmações com as seguintes hipóteses relativas ao custo de capital:

H2a: As empresas que possuem gestão familiar influenciam no custo médio ponderado de capital inferior, quando comparadas com empresas de gestão não familiar;

$\mathrm{H} 2 \mathrm{~b}$ : As empresas familiares que possuem concentração acionária influenciam no custo médio ponderado de capital inferior, quando comparadas com empresas de concentração não familiar;

H2c: As empresas familiares que possuem controle acionário superior influenciam no custo médio ponderado de capital inferior, quando comparadas com empresas de controle não familiar.

\subsection{Método e Procedimentos da Pesquisa}

O universo da pesquisa compreende as 438 companhias listadas na B3, em dezembro de 2017. Inicialmente, optou-se por excluir as empresas financeiras e securitizadoras, o que correspondiam a 114 companhias. Essa escolha deve-se ao desempenho financeiro dessas organizações, que poderia tornar a análise dos resultados tendenciosa. Assim, restaram 324 companhias que foram categorizadas em empresas familiares e não familiares, de acordo com os critérios definidos para gestão, concentração e controle familiar.

Posteriormente, consultou-se a base da Economatica com a finalidade de efetuar a coleta dos dados referente à composição da amostra das 324 empresas. A consulta no Formulário de Referência foi realizada em fevereiro de 2018. Os itens consultados foram: 12.9 (relações familiares), 12.5/6 (composição e experiência profissional da administração e do conselho físcal) e 15.1/2 (posição acionária). Das 324 empresas consultadas, 34 apresentaram inconsistências de informações (passivo circulante, passivo não circulante, patrimônio líquido, despesas financeiras e passivos onerosos), portanto, foram excluídas, resultando uma amostra total de 290 empresas. 
A classificação das 290 empresas listadas na B3 como familiares ou não familiares, nesta pesquisa, fundamentou-se em pesquisas anteriores, visto que uma das principais preocupações em estudos dessa natureza compreende a identificação e o entendimento dos critérios utilizados para definir a amostra. O critério da gestão familiar filia-se ao conceito de McConaughy et al. (2001); Villalonga e Amit (2006); Moura e Beuren (2017), quando determinam que, muitas vezes, o próprio controlador ou um membro da família é o responsável pela gestão. Com base nessas premissas foram identificadas as empresas que possuem membros familiares ocupando o cargo de diretor-presidente ou presidente do conselho de administração.

A definição do critério da concentração acionária familiar baseou-se no conceito amplamente abordado por La Porta et al. (1999). Para os autores, a identificação de uma empresa como familiar tem como requisito a concentração acionária de membros da família com mais de $10 \%$ do total de ações e a participação dos membros da família detentora do capital no conselho de administração.

Para identificar as empresas que possuem controle familiar utilizaram-se os critérios estabelecidos por Guerrero e Barrios (2013), que definem que uma família pode efetivamente controlar as operações da empresa quando possuir mais de $50 \%$ das ações com direito a voto e, ainda, ter membros da família ocupando posições relevantes na gestão, enquanto conselho de administração.

A amostra das 290 empresas retornou com 101 resultados de empresas que cumpriram o requisito da gestão familiar, tendo um membro familiar como diretor-presidente ou um membro familiar como presidente do conselho de administração. Foram listadas 42 empresas que cumpriram o requisito de concentração familiar, tendo pelo menos $10 \%$ de participação do total de ações da companhia. E apenas 12 empresas que detêm controle familiar, sendo companhias que a família detém pelo menos $50 \%$ das ações com direitos a voto.

Para adequar a amostra com o propósito do estudo, assim como dar mais confiabilidade aos dados, foram identificados os outliers - valores atípicos, que se diferenciam drasticamente de todos os outros, ou seja, valores que fogem à normalidade. Segundo Hair, William, Babin, e Anderson (2009), as observações de casos atípicos podem ser excluídas da amostra, pois podem gerar influência indevida sobre os resultados e distorcer seriamente os testes estatísticos. Com base nesse entendimento, foram avaliados os casos atípicos das empresas que apresentaram endividamento total ou custo médio ponderado de capital (CMPC) acima de 500\%, pois esse é um valor que está fora do padrão e muito acima da média de CMPC e do nível de endividamento. Foram excluídas da amostra 7 (sete) empresas que atendiam a uma dessas condições, restando 283 empresas.

De posse dos dados do endividamento total, constatou-se a necessidade de alinhamento interno, observou-se as regras práticas sugeridas por Hair et al. (2009). Calculou-se o intervalo de desvio padrão, multiplicado por 2,5 vezes e somado à média como parâmetro de exclusão para as empresas. Sendo a equação a seguinte:

$$
\begin{gathered}
(\text { Dpadx2,5) + média de end }(=48,05219 \% \times 2,5=120,13048 \%+73,4074 \% \\
=193,53788 \%) .
\end{gathered}
$$

O mesmo procedimento foi realizado no CMPC:

$($ Dpadx2,5) + média do CMPC $(=37,59262 \% x 2,5=93,98155 \%+19,033 \%$ $=113,01455 \%)$.

Foram excluídas as empresas com endividamento superior a 193,53788\%. Na Tabela 1 , dos dados descritivos (283 casos) foram excluídos os casos atípicos (269 casos). 
Tabela 1

Descritivos do endividamento total (END_T) e do CMPC

\begin{tabular}{|c|c|c|c|c|c|}
\hline \multicolumn{2}{|l|}{ Descritivos } & $\begin{array}{c}283 \text { empresas } \\
\text { END_T }\end{array}$ & $\begin{array}{c}* 269 \text { empresas } \\
\text { END_T }\end{array}$ & $\begin{array}{l}283 \text { empresas } \\
\text { CMPC }\end{array}$ & $\begin{array}{c}* * 269 \text { empresas } \\
\text { CMPC }\end{array}$ \\
\hline \multicolumn{2}{|l|}{ Média } & $73,40 \%$ & $65,36 \%$ & $19,03 \%$ & $13,83 \%$ \\
\hline \multirow{2}{*}{$\begin{array}{l}95 \% \\
\text { Intervalo }\end{array}$} & Limite inferior & $67,78 \%$ & $62,21 \%$ & $14,63 \%$ & $12,05 \%$ \\
\hline & \begin{tabular}{|l} 
Limite superior \\
\end{tabular} & $79,03 \%$ & $68,52 \%$ & $23,43 \%$ & $15,61 \%$ \\
\hline \multicolumn{2}{|c|}{$5 \%$ da média aparada } & $67,07 \%$ & $63,96 \%$ & $12,60 \%$ & $11,34 \%$ \\
\hline \multicolumn{2}{|l|}{ Mediana } & $66,79 \%$ & $65,34 \%$ & $9,88 \%$ & $9,70 \%$ \\
\hline \multicolumn{2}{|l|}{ Variância } & 2309,01 & 690,97 & 1413,20 & 220,31 \\
\hline \multicolumn{2}{|c|}{ Desvio Padrão } & $48,05 \%$ & $26,28 \%$ & $37,59 \%$ & $14,84 \%$ \\
\hline \multicolumn{2}{|l|}{ Mínimo } & $10,02 \%$ & $10,02 \%$ & $-2,67 \%$ & $-2,67 \%$ \\
\hline \multicolumn{2}{|l|}{ Máximo } & $397,07 \%$ & $177,08 \%$ & $385,14 \%$ & $106,48 \%$ \\
\hline \multicolumn{2}{|l|}{ Intervalo } & $387,05 \%$ & $167,06 \%$ & $387,81 \%$ & $109,16 \%$ \\
\hline \multicolumn{2}{|c|}{ Intervalo interquartil } & $27,89 \%$ & $27,51 \%$ & $6,03 \%$ & $5,53 \%$ \\
\hline \multicolumn{2}{|c|}{ Assimetria } & 3,262 & ,954 & 6,29 & 4,06 \\
\hline \multicolumn{2}{|l|}{ Curtose } & 14,43 & 2,52 & 47,66 & 18,67 \\
\hline
\end{tabular}

Nota. *Corte de 14 empresas com endividamento acima de 193,53788\%.

**Corte de 14 empresas com endividamento acima de 113,01455\%.

Fonte: Dados da pesquisa (2019).

Percebe-se melhor distribuição dos valores, após a adequação da amostra, que resultou em 269 empresas. A média de endividamento das 283 empresas reduziu de 73,40\% para 65,36\%, resultando em variação positiva de $8,04 \%$. A mediana se ajustou em 65,34 após a exclusão dos casos atípicos. O desvio padrão ficou em $26,28 \%$ e a curtose passou de $14,43 \%$ para $2,52 \%$. A principal adequação da amostra pode ser verificada no endividamento, o mínimo identificado não sofreu alteração, ficando em 10,02\%, porém o endividamento máximo passou de 397,07\% para 17,08\%, deixando os dados mais homogêneos, dando mais confiabilidade à pesquisa.

A média do CMPC das 283 empresas diminui de 19,03\% para 13,83\%, representando variação positiva de $5,2 \%$. Diferença pouco significativa notou-se na mediana que se ajustou em 9,70\% após a exclusão dos casos atípicos. O desvio padrão sofreu ajuste considerável e incidiu de $37,59 \%$ para $14,84 \%$. A curtose resultou em 18,67\%. O mínimo do CMPC não sofreu alteração e está estabelecido em -2,67\%, porém o máximo sofreu adequação relevante, incidindo de 387,81\% para $109,16 \%$, melhorando a homogeneidade das informações.

A Tabela 2 apresenta o constructo com as métricas aplicadas à estrutura de propriedade (gestão, concentração e controle) nas 269 empresas da amostra.

Tabela 2

Estrutura de propriedade (gestão, concentração e controle)

\begin{tabular}{|c|c|c|c|c|}
\hline Variáveis & Subvariáveis & Métricas & Autores & $\begin{array}{c}\text { Fonte de coleta dos } \\
\text { dados }\end{array}$ \\
\hline \multirow{3}{*}{$\begin{array}{l}\text { Tipo de Gestão } \\
\text { (TIPO_GEST) }\end{array}$} & $\begin{array}{l}\text { Diretor-presidente } \\
\text { (Dir_Pres) }\end{array}$ & $\begin{array}{l}\text { Familiar }=1 / \text { não } \\
\text { familiar }=0\end{array}$ & \multirow{3}{*}{$\begin{array}{l}\text { La Porta et al. } \\
(1999) ; \\
\text { McConaughy et } \\
\text { al. }(2001) ; \text { Moura } \\
\text { e Beuren (2017). }\end{array}$} & \multirow{3}{*}{$\begin{array}{l}\text { Sítio eletrônico da B3; } \\
\text { Relatórios Financeiros; } \\
\text { Formulário de } \\
\text { Referência: } \\
\text { Item } 12.9 \text { (relações } \\
\text { familiares) }\end{array}$} \\
\hline & $\begin{array}{l}\text { Presidente do conselho } \\
\text { de administração } \\
\text { (Pres_CA) }\end{array}$ & $\begin{array}{l}\text { Familiar }=1 / \text { não } \\
\text { familiar }=0\end{array}$ & & \\
\hline & $\begin{array}{l}\text { Diretor-presidente e } \\
\text { presidente do conselho } \\
\text { de administração } \\
\text { (DirPres_PresCA) }\end{array}$ & $\begin{array}{l}\text { Familiar }=1 / \text { não } \\
\text { familiar }=0\end{array}$ & & \\
\hline
\end{tabular}




\begin{tabular}{|c|c|c|c|c|}
\hline Variáveis & Subvariáveis & Métricas & Autores & $\begin{array}{c}\text { Fonte de coleta dos } \\
\text { dados }\end{array}$ \\
\hline $\begin{array}{l}\text { Concentração de } \\
\text { Propriedade } \\
\text { (CONC_PROP) }\end{array}$ & $\begin{array}{l}\text { Família possui pelo } \\
\text { menos } 10 \% \text { do total das } \\
\text { ações ordinárias e } \\
\text { preferenciais }\end{array}$ & $\begin{array}{l}\text { Familiar }=1 / \text { não } \\
\text { familiar }=0\end{array}$ & $\begin{array}{l}\text { La Porta et al. } \\
\text { (1999); } \\
\text { McConaughy et } \\
\text { al. (2001); } \\
\text { Correia, Costa e } \\
\text { Lucena (2017). }\end{array}$ & $\begin{array}{l}\text { Sítio eletrônico da B3; } \\
\text { Relatórios Financeiros; } \\
\text { Formulário de } \\
\text { Referência: } \\
\text { Item } 12.5 / 6 \text { (composição } \\
\text { e experiência profissional } \\
\text { da administração e do } \\
\text { conselho fiscal) }\end{array}$ \\
\hline \multirow{2}{*}{$\begin{array}{l}\text { Estrutura de } \\
\text { Controle } \\
(\mathrm{EST}+\mathrm{CONT})\end{array}$} & $\begin{array}{l}\text { Acionista controlador } \\
\text { (se tiver familiar como } \\
\text { acionista controlador } \\
\text { recebe } 1, \text { senão } 0 \text { ) }\end{array}$ & $\begin{array}{l}\text { Familiar }=1 / \text { não } \\
\text { familiar }=0\end{array}$ & \multirow{2}{*}{$\begin{array}{l}\text { McConaughy et } \\
\text { al. }(2001) ; \\
\text { Guerrero e } \\
\text { Barrios (2013); } \\
\text { Moura (2014). }\end{array}$} & \multirow{2}{*}{$\begin{array}{l}\text { Sítio eletrônico da B3; } \\
\text { Relatórios Financeiros; } \\
\text { Formulário de } \\
\text { Referência: } \\
\text { Item } 15.1 / 2 \text { (posição } \\
\text { acionária) }\end{array}$} \\
\hline & $\begin{array}{l}\text { Família com } 50 \% \\
\text { mínimo de ações } \\
\text { ordinárias recebe } 1 \text {, } \\
\text { senão } 0\end{array}$ & $\begin{array}{l}\text { Familiar }=1 / \text { não } \\
\text { familiar }=0\end{array}$ & & \\
\hline
\end{tabular}

Fonte: Elaborada pelos autores (2019).

$\mathrm{Na}$ Tabela 3 a relação das variáveis que integram a estrutura de capital e o nível de endividamento das empresas familiares pesquisadas.

Tabela 3

Estrutura de capital

\begin{tabular}{|c|c|c|c|c|}
\hline Variáveis & Subvariáveis & Métricas & Autores & $\begin{array}{|lll|}\begin{array}{l}\text { Fonte } \\
\text { dados }\end{array} & \text { coleta } \\
\end{array}$ \\
\hline \multirow{3}{*}{ 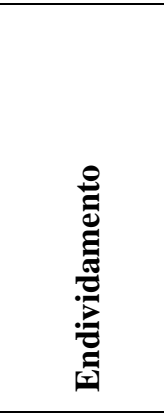 } & $\begin{array}{l}\text { Endividamento } \\
\text { de curto prazo } \\
\text { (END_CURT) }\end{array}$ & $=\frac{\text { Passivo Circulante. }}{\text { Ativo Total }}$ & $\begin{array}{l}\text { Bastos e Nakamura } \\
\text { (2009), Correa, Basso e } \\
\text { Nakamura (2013). }\end{array}$ & Economatica \\
\hline & $\begin{array}{l}\text { Endividamento } \\
\text { de longo prazo } \\
\text { (END_LONG) }\end{array}$ & $=\frac{\text { Passivo Não Circulante }}{\text { Ativo Total }}$ & \begin{tabular}{lcc|} 
Bastos & e & \multicolumn{2}{c|}{ Nakamura } \\
$(2009)$, & Correa et al. \\
$(2013)$. & & \\
\end{tabular} & Economatica \\
\hline & $\begin{array}{l}\text { Endividamento } \\
\text { total } \\
(\text { END_TOT })\end{array}$ & $=\frac{\text { Pas.Circ }+ \text { Pas. Não Circ. }}{\text { Ativo Total }}$ & $\begin{array}{l}\text { Segura, Formigoni, et al. } \\
\text { (2013); Segura, Oliveira } \\
\text { et al. }(2013) .\end{array}$ & Economatica \\
\hline \multirow{3}{*}{ 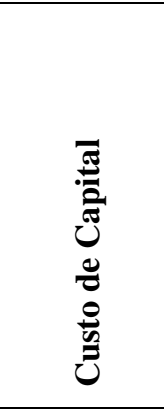 } & $\begin{array}{l}\text { Custo de capital } \\
\text { próprio } \\
(\mathrm{CAPM}) \\
\end{array}$ & $\begin{array}{l}C A P M=R f+\operatorname{beta}[E(R m)-R f]+ \\
\text { risco } / \mathrm{Br}\end{array}$ & $\begin{array}{l}\text { Young e O’Byrne } \\
\text { (2003); Assaf (2012). }\end{array}$ & $\begin{array}{ll}\text { Banco Central do } \\
\text { Brasil. }\end{array}$ \\
\hline & \begin{tabular}{|lr|}
\multicolumn{2}{|l|}{ Custo de capital } \\
de & terceiros \\
$(\mathrm{Kd})$ & \\
\end{tabular} & $\begin{array}{l}\mathrm{Kd}=(1-\text { Imposto de renda) } \mathrm{x} \\
\text { (Despesa Financeira / valor dos } \\
\text { financiamentos. }\end{array}$ & Assaf (2012). & Economatica. \\
\hline & $\begin{array}{l}\text { Custo Médio } \\
\text { Ponderado de } \\
\text { Capital } \\
\text { (CMPC) } \\
\end{array}$ & 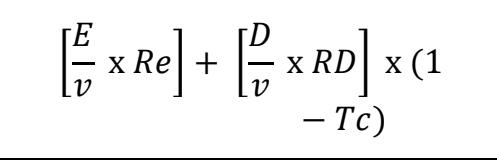 & $\begin{array}{l}\text { Gitman e Madura (2003); } \\
\text { Assaf (2012); Oro, } \\
\text { Beuren e Hein (2009). }\end{array}$ & Economatica \\
\hline
\end{tabular}

Fonte: Elaborada pelos autores (2019).

A definição dos indicadores a serem utilizados para definir os fatores que determinam a estrutura de capital diz respeito ao endividamento total, endividamento de curto e de longo prazo. $\mathrm{O}$ período selecionado para a coleta de dados referente à estrutura de capital e os indicadores selecionados foi o exercício de 2017.

Os dados foram analisados com auxílio do software SPSS e os métodos de análise utilizados foram análise descritiva, correlação e regressão linear. 


\section{DISCUSSÃO E ANÁLISE DOS RESULTADOS}

Nesta seção, abordam-se as discussões dos dados e os resultados evidenciados na pesquisa. A amostra das 269 empresas é composta por 9 diferentes setores econômicos, distribuídos em vários segmentos de empresas que negociam ações no mercado acionário da B3, conforme pode ser visualizado na Tabela 4.

Tabela 4

\section{Segmentação da amostra}

\begin{tabular}{lccccc}
\hline \multirow{2}{*}{ Setor Econômico } & \multicolumn{2}{c}{ Não familiares } & \multicolumn{2}{c}{ Familiares } & \multirow{2}{*}{ Total } \\
\cline { 2 - 5 } & $\mathbf{N}^{\mathbf{0}}$ empresas & $\mathbf{\%}$ & $\mathbf{N}^{\mathbf{0}}$ empresas & $\mathbf{\%}$ & 48 \\
Bens Industriais & 26 & $15,03 \%$ & 22 & $22,92 \%$ & 35 \\
Consumo cíclico & 27 & $15,61 \%$ & 38 & $39,58 \%$ & 65 \\
Consumo não cíclico & 11 & $6,36 \%$ & 10 & $10,42 \%$ & 21 \\
Materiais básicos & 15 & $8,67 \%$ & 9 & $9,38 \%$ & 24 \\
Petróleo e gás & 5 & $2,89 \%$ & 3 & $3,13 \%$ & 8 \\
Saúde & 7 & $4,05 \%$ & 5 & $5,21 \%$ & 12 \\
Tecnologia da informação & 4 & $2,31 \%$ & 5 & $5,21 \%$ & 9 \\
Telecomunicações & 5 & $2,89 \%$ & 0 & $0,00 \%$ & 5 \\
Utilidades públicas & 73 & $42,20 \%$ & 4 & $4,17 \%$ & 77 \\
Total & $\mathbf{1 7 3}$ & $\mathbf{1 0 0 , 0 \%}$ & $\mathbf{9 6}$ & $\mathbf{1 0 0 , 0 0 \%}$ & $\mathbf{2 6 9}$ \\
\hline
\end{tabular}

Fonte: Dados da pesquisa (2019).

Na Tabela 4 pode-se visualizar que 173 empresas têm gestão classificada como não familiar, sendo 42,2\% representadas pelo setor de utilidades públicas. Em contrapartida, a amostra de empresas classificadas com gestão familiar é composta por 96 casos, 39,58\% lotadas no setor de consumo cíclico.

Dois pontos relevantes podem ser considerados nesta análise. Primeiramente, dentre todos os setores, apenas telecomunicações não tem nenhum caso de empresas classificadas com gestão familiar. Embora o setor seja composto de apenas 5 empresas, caracteriza uma especificidade setorial quanto a não ocorrência desse tipo de gestão. Outro ponto evidenciado é a distribuição de empresas do setor de utilidade pública. Diferentemente do setor de telecomunicações, este possui uma quantidade significativa de empresas vinculadas. Entretanto, das 77 empresas listadas, apenas 4 são familiares, expondo uma situação atípica, tendo em vista que todas as demais possuem distribuição equilibrada no setor.

$\mathrm{Na}$ sequência, realizou-se análise descritiva das variáveis utilizadas na pesquisa. Os resultados podem ser visualizados na Tabela 5 .

Tabela 5

\section{Análise descritiva}

\begin{tabular}{lccccc}
\hline \multicolumn{1}{c}{ Variável } & Mínimo & Máximo & Média & Desvio Padrão & Variância \\
\hline Gestão & 0 & 1 & 0,36 & 0,480 & 0,230 \\
Concentração & 0 & 1 & 0,14 & 0,349 & 0,122 \\
Controle & 0 & 1 & 0,04 & 0,198 & 0,039 \\
Custo_P & $0,4 \%$ & $16,2 \%$ & $8,2 \%$ & 2,5 & 6,226 \\
Custo_T & $0,7 \%$ & $242,7 \%$ & $26,3 \%$ & 33,3 & 1108,327 \\
WACC & $2,7 \%$ & $106,5 \%$ & $13,8 \%$ & 14,8 & 220,310 \\
End_CP & $2,5 \%$ & $150,1 \%$ & $29,6 \%$ & 20,9 & 436,108 \\
End_LP & $0,4 \%$ & $110,4 \%$ & $35,7 \%$ & 20,6 & 423,038 \\
End_TT & $10,0 \%$ & $177,1 \%$ & $65,4 \%$ & 26,3 & 690,977 \\
N válido (listwise) & 269 & & & & \\
\hline Fonte:Dados & & & &
\end{tabular}

Fonte: Dados da pesquisa. 
Na Tabela 5 pode-se visualizar a composição descritiva dos dados da amostra selecionada. Para as variáveis Gestão, Concentração e Controle, o mínimo apresentado foi 0 e o máximo foi 1, tendo em vista que essas variáveis possuem característica Dummy. As demais variáveis apresentam valores mais dispersos e com maiores desvios padrão, em razão do custo de capital e da composição do endividamento apresentarem-se desequilibrados.

Na sequência, foram calculados os coeficientes de correlação das variáveis. Para tanto, a amostra final utilizada para composição da análise permaneceu sendo 269 empresas, cujos resultados podem ser evidenciados na Tabela 6.

Tabela 6

\section{Coeficientes de Correlação}

\begin{tabular}{llccc}
\hline Variáveis & & Gestão & Concentração & Controle \\
\multirow{2}{*}{ End_CP } & Correlação & 0,053 & 0,041 & 0,082 \\
& Sig. & 0,390 & 0,504 & 0,180 \\
\hline \multirow{2}{*}{ End_LP } & Correlação & $\mathbf{- 0 , 2 1 3 * *}$ & $\mathbf{- 0 , 1 4 9 *}$ & $-0,081$ \\
\multirow{2}{*}{ End_TT } & Sig. & 0,000 & 0,015 & 0,185 \\
& Correlação & $\mathbf{- 0 , 1 2 5 *}$ & $-0,084$ & 0,002 \\
\multirow{2}{*}{ Custo_Próprio } & Sig. & 0,040 & 0,171 & 0,978 \\
\hline \multirow{2}{*}{ Custo_Terceiros } & Correlação & $-0,103$ & $-0,038$ & 0,055 \\
& Sig. & 0,091 & 0,536 & 0,368 \\
\hline \multirow{2}{*}{ WACC } & Correlação & 0,083 & 0,007 & 0,028 \\
& Sig. & 0,177 & 0,909 & 0,644 \\
\hline \multirow{2}{*}{ Nota. } & Correlação & 0,029 & 0,012 & 0,082 \\
& Sig. & 0,632 & 0,848 & 0,182 \\
\hline
\end{tabular}

Nota. *A correlação é significativa no nível 0,05 (bilateral).

**A correlação é significativa no nível 0,01 (bilateral).

Fonte: dados da pesquisa (2019).

Três associações apresentaram significância na análise de correlação apresentada da Tabela 6. Inicialmente verificou-se que duas variáveis se apresentaram significativamente associáveis à variável de membros familiares na gestão, sendo o Endividamento de Longo Prazo e o Endividamento Total. Para ambas as situações, o coeficiente apresentou-se negativo, o que denota uma relação inversamente proporcional entre as variáveis. Tendo em vista que na variável Dummy o maior valor representava a ocorrência de membro familiar na gestão, pode-se interpretar que há tendência de empresas com Gestão Familiar apresentarem endividamento de longo prazo menor que empresas não familiares. $\mathrm{O}$ mesmo comportamento pôde ser evidenciado no endividamento total, cujo coeficiente se apresentou significativamente associado à ocorrência de gestão familiar, e da mesma forma, inversamente proporcional.

Esses resultados vão ao encontro daqueles evidenciados por La Porta et al. (1999). Os resultados encontrados pelos autores, comparados com os achados desta investigação, permitem inferir que essas variáveis endógenas tendem a influenciar aspectos de gestão quando analisadas sob a ótica da estrutura e custo de capital da empresa. Outra constatação coaduna com os achados de Segura, Formigoni, et al. (2013), cuja evidência revela empresas familiares possuírem menor endividamento.

$\mathrm{Na}$ associação das variáveis com a Concentração Acionária Familiar, apenas uma associação se apresentou significativa. A relação entre esta e o endividamento de longo prazo trouxe um coeficiente de $-0,149$, com significância em nível 0,05 . Novamente observa-se uma característica inversa, denotando que empresas com concentração acionária familiar tendem a apresentar menor endividamento de longo prazo, quando comparadas às demais. Por fim, as associações realizadas com a variável Controle Acionário Familiar não apresentaram nenhuma significância. Esses resultados divergem daqueles encontrados por Lanzarin (2017), enquanto os resultados do autor demonstram um alinhamento significativo entre a gestão familiar e o custo da dívida da organização, essa evidência não foi constatada nesta pesquisa. 
Apresentados os resultados da correlação das variáveis da pesquisa, passa-se a mensurar a existência de influência dos fatores de gestão, concentração acionária e controle acionário no endividamento e no custo do capital. Dessa forma, realizou-se, mediante estatística multivariada de dados, o teste de regressão linear, cujos dados podem ser evidenciados na Tabela 7.

Tabela 7

Regressão linear dos dados

\begin{tabular}{llccccc}
\hline $\begin{array}{l}\text { Variável } \\
\text { Dependente }\end{array}$ & $\begin{array}{l}\text { Variável } \\
\text { Independente }\end{array}$ & R2 & F & B & t & Sig. \\
\hline \multirow{3}{*}{ Endividamento } & Gestão & 0,016 & 4,249 & $-6,854$ & $-2,061$ & $0,040^{*}$ \\
& Concentração & 0,012 & 1,882 & $-6,303$ & $-1,372$ & $0,001^{*}$ \\
& Controle & 0,000 & 0,001 & 0,227 & 0,028 & 0,978 \\
\hline \multirow{3}{*}{ WACC } & Gestão & 0,001 & 0,229 & 0,906 & 0,479 & 0,632 \\
& Concentração & 0,000 & 0,037 & 0,498 & 0,191 & 0,848 \\
& Controle & 0,007 & 1,787 & 6,100 & 1,337 & 0,182 \\
\hline
\end{tabular}

Fonte: Dados da pesquisa (2019).

Duas análises apresentaram resultados significativos no teste de regressão linear. Como pode ser visualizado na Tabela 7, os testes apresentaram significância das variáveis independentes Gestão Familiar e Concentração Acionária em relação ao endividamento das organizações pesquisadas. Verifica-se em ambos que a influência das variáveis independentes é inversamente proporcional, ou seja, empresas que possuem gestão familiar apresentam menor endividamento. Da mesma maneira, os resultados demonstram a influência inversamente proporcional em relação à concentração, o que denota que empresas que possuem concentração acionária também apresentam menor endividamento.

Os resultados aqui encontrados coadunam com as evidências apontadas por La Porta et al. (1999), que analisaram a estrutura de propriedade em empresas nas economias mais ricas no mundo. Constatou-se que em empresas familiares cujos acionistas controladores têm poder significativo na gestão, o endividamento é inferior quando comparadas com empresas não familiares. Esse resultado coaduna ainda com as evidências de Segura, Formigoni, et al. (2013) e com Segura, Oliveira, et al. (2013), que constataram que entidades com influência familiar na gestão são menos endividadas do que as companhias não familiares. Diverge, entretanto, do posicionamento recente de Kayo et al. (2018), que defendem que empresas familiares são mais confiantes e, para tanto, mais propensas a riscos.

$\mathrm{O}$ fato de os testes que relacionaram a influência familiar no custo de capital das empresas não terem apresentado influência significativa nesta investigação, divergem dos achados de McConaughy et al. (2001) e de Lanzarin (2017), que encontraram alinhamento de interesses na perspectiva da Teoria da Agência, o que reflete no custo de financiamento da dívida. Esse resultado implica dizer que, mesmo com a gestão, a concentração acionária ou o controle acionário estar em poder da família, o custo de capital não sofre alterações significativas.

Tendo em vista os resultados encontrados e debatidos no decorrer desta seção, é possível compor um quadro resumo, que apresente o resultado da validação das hipóteses propostas, conforme pode ser visualizado na Tabela 8 . 
Tabela 8

Resumo das Hipóteses

\begin{tabular}{c|l|c}
\hline Hipótese & \multicolumn{1}{c}{ Relação } & Status \\
\hline H1a & Gestão Familiar $\longrightarrow$ Endividamento & Aceita \\
\hline H1b & Concentração Acionária $\longrightarrow$ Endividamento & Aceita \\
\hline H1c & Controle Acionário $\longrightarrow$ Endividamento & Rejeita \\
\hline H2a & Gestão Familiar $\longrightarrow$ Custo de Capital & Rejeita \\
\hline H2b & Concentração Acionária $\longrightarrow$ Custo de Capital & Rejeita \\
\hline H2c & Controle Acionário $\longrightarrow$ Custo de Capital & R
\end{tabular}

Fonte: Dados da pesquisa (2019).

Nota-se que dentre as hipóteses propostas, somente duas foram aceitas. A hipótese H1a, que propunha que as empresas que possuem membros familiares na gestão possuem um endividamento inferior quando comparadas às empresas de gestão não familiar, foi aceita, ou seja, denota-se que empresas com gestão familiar possuem endividamento menor que empresas não familiares. A mesma conclusão pode ser alcançada na avaliação da $\mathrm{H} 1 \mathrm{~b}$, pois restou comprovado que empresas que possuem concentração acionária familiar influenciam o endividamento inferior, quando comparadas com empresas de concentração não familiar.

A hipótese H1c, que buscava mensurar se empresas que possuem controle acionário familiar influenciam o endividamento inferior, quando comparadas com empresas não familiares, restou rejeitada, tendo em vista que a análise realizada por meio do coeficiente de correlação e determinação não apresentou significância.

Apresentados os resultados quanto às hipóteses que avaliavam a composição do endividamento, segue-se para aqueles relacionados ao custo de capital. Nota-se que nessa avaliação, todas as hipóteses foram rejeitadas, ou seja, os resultados da influência da gestão familiar, da concentração acionária e do controle acionário no custo de capital restaram inexitosos, o que tornou a rejeitar as hipóteses $\mathrm{H} 2 \mathrm{a}, \mathrm{H} 2 \mathrm{~b}$ e $\mathrm{H} 2 \mathrm{c}$.

Apresentada a discussão dos resultados, na seção seguinte são expostas as considerações do estudo, limitações e sugestões para novas investigações.

\section{CONSIDERAÇÕES FINAIS}

Este estudo objetivou mensurar a influência da propriedade sob os aspectos de gestão familiar, concentração acionária e controle acionário na estrutura de capital, cujas variáveis foram compostas por indicadores de endividamento e custo de capital, comparando empresas familiares com empresas não familiares listadas na B3.

O estudo, realizado com dados resgatados da base de dados Economatica, apresenta característica descritiva com abordagem quantitativa. A amostra da pesquisa consistiu de 269 empresas familiares e não familiares. Na descrição da revisão de literatura, foi possível a construção de 6 hipóteses que observaram as dimensões de propriedade, endividamento e custo de capital.

Os resultados demonstraram que a gestão familiar e a concentração acionária influenciam significativamente no endividamento das empresas, ou seja, empresas familiares tendem a apresentar-se menos endividadas. Essa condição permitiu a confirmação de duas das seis hipóteses propostas. $\mathrm{O}$ controle acionário em empresas familiares não se mostrou significante nas análises propostas.

Outras três hipóteses que mensuraram a gestão familiar, a concentração acionária e o controle acionário em relação ao custo de capital, foram rejeitadas, não tendo apresentado qualquer 
nível de significância nas relações propostas. Esse resultado vem de encontro a outros estudos, que evidenciaram significativas influências nessas relações.

O estudo apresentou algumas limitações, entre elas a análise ter sido realizada em um período único (2017), bem como a utilização unicamente de empresas de capital aberto. Embora os dados tenham sido resgatados em bases de dados secundárias, os resultados não podem ser generalizados, haja vista que a amostra utilizada não compreende características da grande maioria das empresas.

Sugere-se para futuras investigações que sejam utilizados dados longitudinais, permitindo compreender a evolução do comportamento desses indicadores. A utilização de séries temporais e dados em painel, possivelmente, trará subsídios mais detalhados dos motivos que fizeram com que as hipóteses propostas fossem rejeitadas, mesmo com estudos correlatos tendo evidenciado resultados distintos daqueles apresentados nesta investigação.

\section{REFERÊNCIAS}

Adams, R., Almeida, H. A., \& Ferreira, D. (2009). Understanding the relationship between founder-CEOs and firmperformance. Journal of Empirical Finance, 16, 136-150.

Anderson, R. C., Mansi, S. A., \& Reeb, D. M. (2003). Founding family ownership and the agency cost of debt. Journal of Financial Economics, 68, 263-285.

Anderson, R. C., \& Reeb, D. M. (2003). Founding-Family Ownership, Corporate diversification, and firm leverage. Journal of Law and Economics, 46, 653-684.

Aronoff, C. E., McClure, S. L., \& Ward, J. L. (2011). Family business succession: the final test for greatness. Marietta: Family Enterprise.

Assaf, A., Nt. (2012). Finanças corporativas e valor. São Paulo: Atlas.

Bastos, D. D., \& Nakamura, W. T. (2009). Determinantes da estrutura de capital das companhias abertas no Brasil, México e Chile no período 2001-2006. Revista Contabilidade \& Finanças, 20(50), 75-94.

Bernhoeft, R. (2004, janeiro 29). Evolução na empresa familiar. Gazeta Mercantil, São Paulo.

Bethlem, A. (2004). Estratégia empresarial: conceitos, processos e administração estratégica (5a ed.). São Paulo: Atlas.

Carvalhal da Silva, A. L. (2006). Governança corporativa e sucesso empresarial: melhores práticas para aumentar o valor da firma. São Paulo: Saraiva.

Charbel, S., Elie, B., \& Georges, S. (2013). Impact of family involvement in ownership management and direction on financial performance of the Lebanese firms. International Strategic Management Review, 1(1), 30-41.

Claessens, S., Djankov, S., \& Lang, L. H. P. (2000). The separation of ownership and control in East Asian corporations. Journal of Financial Economics, 58(1-2), 81-112.

Claessens, S., Djankov, S., Fan, J. P. H., \& Lang, L. H. P. (2002). Disentangling the incentive and entrenchment effects of large shareholdings. Journal of Finance, 57, 2741-2771. 
Correa, C. A., Basso, L. F. C., \& Nakamura, W. T. (2013). Estrutura de Capital das Maiores Empresas Brasileiras: Análise Empírica das Teorias de Pecking Order e Tradeoff, Usando Panel Data. Revista de Administração Mackenzie, 14(4), 106-133.

Correia, T. S., Costa, I. L. S., \& Lucena, W. G. L. (2017). O Impacto da Governança corporativa: Conselho de Administração, Estrutura de Propriedade e Controle e as Informações Socioambientais nas Companhias Abertas. Teoria e Prática em Administração, 7(2), 156-182.

Crisóstomo, V. L., \& Pinheiro, B. G. (2015). Estrutura de Capital e concentração de propriedade da empresa brasileira. Revista de Finanças Aplicadas, 4, 1-30.

Dal Vesco, D. G., \& Beuren, I. M. (2015). Influência da estrutura de propriedade e dos interlocking entre proprietários no desempenho das empresas. Revista Contabilidade Vista e Revista, 26(3), 49-79.

Dyer, G. W. (1988). Culture and continuity in the Family firms. Family Bussiness Review, 1(1), 37-50.

Erbetta, F., Menozzi, A., Corbetta, G., \& Fraquelli, G. (2013). Assessing family firm performance using frontier analysis techniques: Evidence from Italian manufacturing industries. Journal of Family Business Strategy, 4(2), 106-117.

Faccio, M., \& Lang, L. (2002). The Ultimate Ownership of Western European Corporations. Journal of Financial Economics, 65(3), 365-395.

Fonseca, C. V. C., \& Silveira, R. L. F. (2016). Governança corporativa e custo de capital de terceiros: evidências entre empresas brasileiras de capital aberto. Revista Eletrônica de Administração, 83(1), 106-133.

Gao, N., \& Jain, B. A. (2011). Founder CEO management and the long-run investment performance of IPO firms. Journal of Banking \& Finance, 35, 1669-1682.

Gitman, L. J., \& Madura, J. (2003). Administração financeira: uma abordagem gerencial (2a ed.). Porto Alegre: Bookman.

González, M., Guzmán, A., Pombo, C., \& Trujillo, M.-A. (2013). Family firms and debt: Risk aversion versus risk of losing control. Journal of Business Research, 6.

Guerrero, L. M. O., \& Barrios, M. A. (2013). Gerencia de las empresas familiares y no familiares: análisis comparativo. Estudios Gerenciales, 29, 293-302.

Hair, J. F., Jr., William, B., Babin, B., \& Anderson, R. (2009). Análise multivariada de dados (6a ed.). Porto Alegre: Bookman.

Hautz, J., Mayer, M. C. J., \& Stadler, C. (2013). Ownership identify and concetration: A study of their joint impacto n corporate diversification. British Journal of Management, 24, 102-126.

Hsu, H-H., Lin, C-H., \& Tsao, S-M. (2018). Founding family and auditor choice: evidence from Taiwan. Corp Govern Int Rev, 26, 118-142. 
Kayo, E. K., Brunaldi, E. O., \& Aldrighi, D. M. (2018). Capital Structure Adjustment in Brazilian Family Firms, Revista de Administração Contemporânea, 22(1), 92-114.

La Porta, R., Lopez-De-Silanes, F., \& Shleifer, A. (1999). Corporate owernship around the world. Journal of Finance, 54(2), 471-517.

Lanzarin, J. (2017). Influência da estrutura de propriedade e da gestão familiar no custo de financiamento da dívida de companhias abertas. Dissertação de Mestrado, Universidade Comunitária da Região de Chapecó, Chapecó, Santa Catarina, Brasil.

López-Gracia, J., \& Sánchez-Andújar, S. (2007). Financial Structure of the Family Business: Evidence From a Group of Small Spanish Firms. Family Business Review, 20(4), 269-287.

McConaughy, D., Matthews, C. H., \& Fialko, A. S. (2001). Founding family controlled firms: performance, risk and value. Journal of Small Business Management, 39(1), 31-49.

Moura, G. D. de. (2014). Influência da estrutura de propriedade e da gestão familiar no posicionamento em fusões e aquisições. Tese de Doutorado, Universidade Regional de Blumenau, Blumenau, Santa Catarina, Brasil.

Moura, G. D., \& Beuren, I. M. (2017). Influência da estrutura de propriedade e do gerenciamento familiar sobre o posicionamento em fusões e aquisições. Revista Faculdad de Ciencias Económicas, 25(1), 129-149.

Oro, I. M., Beuren, I. M., \& Hein, N. (2009). Análise da relação entre a estrutura de capital e o lucro operacional nas diversas gerações de empresas familiares brasileiras. Revista Contabilidade Vista \& Revista, 20(1), 67-94.

Oro, I. M., Beuren, I. M., \& Hein, N. (2009). Análise da eficiência de empresas familiares brasileiras. Revista de Administração de Empresas Eletrônica, 8(2).

Ribeiro, F., Colauto, R. D., \& Clemente, A. (2016). Determinantes da Formação de Board Interlocking no Mercado de Capitais Brasileiro. Revista de Educação e Pesquisa em Contabilidade, 10(4), 398-415.

Sampaio, R. B. Q., Lima, B. C. C., Cabral, A. C. A., \& Paula, A. L. B. de. (2014). A governança corporativa e o retorno das ações de empresas de controle familiar e de controle não familiar no Brasil. Revista de Gestão, 21(2), 219-234.

San Martin Reyna, J. M., \& Duran-Encalada, J. A. (2012). The relationship among family business, corporate governance and firm performance: Evidence from the Mexican stock exchange. Journal of Family Business Strategy, 3(2), 106-117.

Segura, L. C., Formigoni, H., \& Merofa, P. A. (2013). Um estudo sobre a influência do controle e gestão familiar no endividamento das empresas abertas brasileiras. Anais eletrônicos do Congresso Brasileiro de Custos, Uberlândia, 20.

Segura, L. C., Oliveira, C. G., Olyveira, M. G. A. S., \& Souza, S. A. Uma análise do endividamento das empresas familiares brasileiras nos diversos setores da economia. Anais eletrônicos do Semead - Seminário de Administração, São Paulo, 16. 
Villalonga, B., \& Amit, R. (2006). How do family ownership, management and control affect firm value? Journal of Financial Economics, 80(2), 385-417.

Young, S. D., \& O’ Byrne, S. F. (2003). EVA e gestão baseada em valor: guia prático para implementação. São Paulo: Artmed. 